\title{
$\mathrm{MFC}$ 와 능동 제어를 이용한 손상된 복합재의 동적 특성 복원
}

\section{Dynamic Characteristics Modification of Damaged Composite Structure Using MFC and Active Control Algorithm}

\author{
손 정 우*·김 흥 수 ${ }^{\dagger}$ \\ Jung Woo Sohn and Heung Soo Kim
}

(Received October 4, 2013 ; Revised November 22, 2013 ; Accepted November 22, 2013)

Key Words : Active Control(능동 제어), Laminated Composite(적층 복합재), Delamination(층간 분리), Piezoelectric Actuator(압전 작동기), Macro-fiber Composite Actuator(MFC 작동기)

\begin{abstract}
In this work, active control algorithm is adopted to reduce delamination effects of the damaged composite structure and control performance with MFC actuator is numerically evaluated. Finite element model for the damaged composite structure with piezoelectric actuator is established based on improved layerwise theory. In order to achieve high control performance, MFC actuator, which has increased actuating force, is considered as a piezoelectric actuator. Mode shapes and corresponding natural frequencies for the damaged smart composite structure are studied. After design and implementation of active controller, dynamic characteristics of the damaged smart composite structure are investigated.
\end{abstract}

\section{1. 서 론}

지구 온난화에 따른 에너지 이용 효율 증가와 이 산화탄소 배출량 감소를 위한 연구가 전세계적으로 진행되고 있다. 작은 질량을 가지면서도 우수한 강 도와 강성을 가지는 경량 구조물에 대한 연구는 그 중 핵심적인 부분이라 할 수 있다.

일반적으로 적층 복합재 구조물은 뛰어난 비강도 와 비강성을 가지는 것으로 알려져 있어 경량 구조물 의 설계에 활용하기 위한 연구가 활발히 진행되고 있 다. 잘 알려진 바와 같이 미국 보잉사의 787기종의 경우 전체의 $50 \%$ 이상의 구조물에 복합재료가 사용
되어 전체 구조물의 무게를 상당히 줄였으며, 디자이 너 고든 머레이가 설계한 전기 자동차인 T.27의 경우 전체 구조물을 모두 복합재를 사용하여 차량의 경량 화를 통한 에너지 효율 향상을 얻을 수 있었다. 그러 나 이러한 적층 복합재 구조물은 횡 방향 충격하중에 취약하여 층간 분리와 같은 구조물의 손상이 발생할 수 있으며, 층간 분리와 같은 손상은 구조물의 강도 를 크게 떨어뜨리고 수명을 단축시킬 수 있다.

이에 층간 분리와 같은 구조물의 손상을 예측하거 나 실시간으로 파악하는 구조 건전성 평가 기술 등에 대한 연구가 활발히 진행되어왔다. Giurgiutiu 등은 압전 재료와 표면 탄성파를 이용한 적층 복합재 구조 물의 구조 건전성 평가에 대한 연구를 수행하였다 ${ }^{(1,2)}$.

\# A part of this paper was presented and selected as one of best papers at the KSNVE 2013 Annual Autumn Conference

\$ Recommended by Editor Hyung-Jo Jung

(c) The Korean Society for Noise and Vibration Engineering 
Cho 등은 층간 지그재그 변위장을 이용한 적층 구조 물의 층간 분리 거동에 대한 연구를 수행하였다 ${ }^{(3)}$.

또한 구조물에 발생한 손상이 구조물의 동적 특 성 변화에 미치는 영향을 파악하기 위한 연구도 활 발히 진행되고 있다. Chattopadhyay 등은 고차변위 장을 이용하여 복합재 적층판의 정확한 응력 해석 기법을 도입하면서 층간 분리가 있는 복합재 구조물 의 모델을 개발하고 손상이 있는 복합재 구조물의 특성 변화에 대해 고찰하였다 ${ }^{(4 \sim 6)}$. Campanelli는 복 합재에 발생하는 층간 분리가 구조물의 모드 특성에 미치는 영향을 고찰하였다궁. Saravanos는 층간 분 리에 의한 복합재 적층판의 진동 감쇠 특성의 변화 에 대해 보고하였다 ${ }^{(8)}$. Lee는 층간 변위장 모델을 바탕으로 층간 전단 응력의 효과를 모델링하고 적층 보 구조물의 진동 특성을 해석하였다 ${ }^{(9)}$. Kim 등은 압전 재료를 이용하여 층간 분리가 있는 복합재 구 조물의 동적 특성 변화를 관찰하였다 ${ }^{(10)}$. 층간 분리 가 발생하면 구조물의 강성이 저하되고 이에 따라 고유진동수가 감소하게 된다. 감소된 고유진동수가 작동 주파수 영역에 근접하는 경우, 공진 현상으로 인해 구조물의 파괴가 발생할 수 있으므로 층간 분 리에 의해 구조물의 동적 특성이 변하는 것은 방지 해야 한다. 최근 플라스틱 수지 등을 이용하여 복합 재 구조물에 발생한 층간 분리 손상을 일시적으로 치유하는 연구가 진행되었다 ${ }^{(11,12)}$. 그러나 구조물에 발생된 손상이 구조물의 특성 변화에 미치는 효과를 감소시키고 구조물의 특성을 유지하기 위해 압전 작 동기와 능동제어 기법을 이용한 연구는 현재까지는 이루어지지 않고 있다.

이 연구에서는 손상이 있는 적층 복합재에 $\mathrm{MFC}$ 작동기와 능동 제어 알고리즘을 적용하여, 손상이

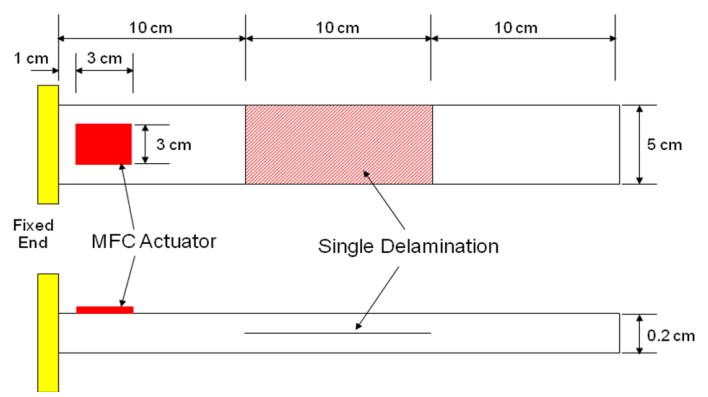

Fig. 1 Configuration of the proposed composite structure
구조물의 특성 변화에 주는 영향을 줄이고, 구조물 의 동적 특성을 유지할 수 있는지 평가하였다. 향상 된 층간 변위장 모델을 이용하여 손상이 있는 복합 재 구조물에 대한 유한요소 모델을 구축하고, 이를 바탕으로 구조물의 모드 특성을 확인하였다. 구조물 의 제어를 위해 향상된 작동력을 갖는 $\mathrm{MFC}$ 작동기 를 고려하였고, 능동 제어기를 설계하고 이를 적용 하여 손상에 의한 구조물의 특성 변화 효과를 능동 적으로 감소시킬 수 있는지 확인하였다.

\section{2. 시스템 모델링}

이 연구에서 고려된 층간 분리가 있는 적층 복합 재 구조물을 Fig. 1에 나타내었다. 구조물은 한 쪽 끝 단이 고정된 외팔보 형태이며 길이는 $30 \mathrm{~cm}$, 폭 은 $5 \mathrm{~cm}$, 두께는 $0.2 \mathrm{~cm}$ 이다. 구조물의 표면에는 길 이 $3 \mathrm{~cm}$, 폭 $3 \mathrm{~cm}$, 두께 $0.3 \mathrm{~cm}$ 의 $\mathrm{MFC}$ 작동기가 고정된 끝 단으로부터 $1 \mathrm{~cm}$ 떨어진 위치에 부착되 어 있으며, 완벽하게 부착되어 있다는 가정을 통하 여 접착제의 두께 등에 의한 영향은 고려하지 않는 다. 구조물의 두께 방향 가운데 면에 층간 분리 형 태의 손상이 존재하는 것으로 가정하였으며, 층간 분리 면의 크기는 길이 $10 \mathrm{~cm}$, 폭 $5 \mathrm{~cm}$ 이고, 고정된 끝 단으로부터 $10 \mathrm{~cm}$ 떨어진 곳에 위치한다. 복합재 의 적층 배열은 0 과 90 로 8 층을 교차 적층하고,

Table 1 Material properties

\begin{tabular}{|c|c|c|c|}
\hline \multicolumn{4}{|c|}{ Carbon cyanate } \\
\hline $\begin{array}{c}\text { Young's } \\
\text { modulus } E_{1}\end{array}$ & $380 \mathrm{GPa}$ & $\begin{array}{c}\text { Young's } \\
\text { modulus } E_{2}\end{array}$ & $16.6 \mathrm{GPa}$ \\
\hline $\begin{array}{c}\text { Shear } \\
\text { modulus } G_{12}\end{array}$ & $4.2 \mathrm{GPa}$ & Density $\rho$ & $1800 \mathrm{~kg} / \mathrm{m}^{3}$ \\
\hline $\begin{array}{c}\text { Poisson ratio } \\
v_{12}\end{array}$ & 0.31 & $\begin{array}{c}\text { Poisson ratio } \\
v_{23}\end{array}$ & 0.42 \\
\hline \multicolumn{4}{|c|}{ MFC(poling direction: 1 ) } \\
\hline $\begin{array}{c}\text { Young's } \\
\text { modulus } E_{1}\end{array}$ & 30 GPa & $\begin{array}{c}\text { Young's } \\
\text { modulus } E_{2}\end{array}$ & 15.86 GPa \\
\hline $\begin{array}{c}\text { Shear } \\
\text { modulus } G_{12}\end{array}$ & $5.52 \mathrm{GPa}$ & Density $\rho$ & $7750 \mathrm{~kg} / \mathrm{m}^{3}$ \\
\hline $\begin{array}{c}\text { Poisson ratio } \\
v_{12} \\
\end{array}$ & 0.31 & $\begin{array}{c}\text { Poisson ratio } \\
v_{21}\end{array}$ & 0.16 \\
\hline $\begin{array}{l}\text { Piezoelectric } \\
\text { constant } d_{11}\end{array}$ & $400 \mathrm{pC} / \mathrm{N}$ & $\begin{array}{l}\text { Piezoelectric } \\
\text { constant } d_{12}\end{array}$ & $-170 \mathrm{pC} / \mathrm{N}$ \\
\hline $\begin{array}{c}\text { Permittivity } \\
\varepsilon_{11} / \varepsilon_{0}\end{array}$ & 0.31 & $\begin{array}{c}\text { Permittivity } \\
\varepsilon_{22} / \varepsilon_{0}\end{array}$ & 0.16 \\
\hline
\end{tabular}


가운데 면을 중심으로 상하 대칭을 이루는 $[0 / 90] 4 \mathrm{~s}$ 형태이다. 복합재의 재료인 carbon cyanate와 MFC 작동기의 물성치는 Table 1 에 나타내었다.

비등방성 특성을 가지는 적층 복합재 구조물의 모델링에서는 구조물의 변형을 정확하게 표현할 수 있어야 한다. 층간 분리가 존재하는 경우에는 변위 장이 층간 전단응력을 정확하게 나타낼 수 있어야 한다. 따라서 이 연구에서는 향상된 층간 변위장 모 델을 사용하여 층간 분리 모델을 개발하였다. 향상 된 층간 변위장 모델은 적층 복합재의 전체적인 거 동을 묘사하는 1 차 전단 변위장 모델과 두께 방향 의 층간 전단응력의 경계 조건과 연속 조건을 만족 하는 지그재그 층간 변위장 모델의 선형 중첩으로 이루어져 있다. 층간 분리가 있는 복합재의 임의의 좌표 $(x, y, z)$ 에서의 변위는 다음과 같이 표현된다.

$$
\begin{aligned}
U_{1}^{k}(x, y, z, t) & =u_{1}+A_{1}^{k}(z) \phi_{1}+B_{1}^{k}(z) w_{, x} \\
+ & \bar{C}_{1}^{j}(z) \bar{w}_{, x}^{j}+\sum_{j=1}^{N-1} \bar{u}_{1}^{j} H\left(z-z_{j}\right) \\
U_{2}^{k}(x, y, z, t) & =u_{2}+A_{2}^{k}(z) \phi_{2}+B_{2}^{k}(z) w_{, y} \\
+ & \bar{C}_{2}^{j}(z) \bar{w}_{, y}^{j}+\sum_{j=1}^{N-1} \bar{u}_{2}^{j} H\left(z-z_{j}\right) \\
U_{3}^{k}(x, y, z, t) & =w(x, y, t) \\
+ & \sum_{j=1}^{N-1} \bar{w}^{j}(x, y, t) H\left(z-z_{j}\right)
\end{aligned}
$$

여기서 $U_{1}^{k}, U_{2}^{k}$ 는 면내 방향 변위를, $U_{3}^{k}$ 는 두께 방향 변위를 나타낸다. 위첨자 $k$ 는 $k$ 번째 적층판을 나타낸다. 그리고, $u_{1}, u_{2}, w$ 는 기준면에서의 변위를 나타내고, $\phi_{1}, \phi_{2}$ 는 기준면에서 수직인 방향에 대 해서 $x, y$ 방향으로의 회전을 나타낸다. 층간 분리 를 묘사하기 위해서 독립 변위인 $\bar{u}_{1}^{j}, \bar{u}_{2}^{j}, \bar{w}^{j}$ 가 도입되었으며, 이 항들은 층간 분리부 사이에서 나 타나는 미끄러짐이나 급작스러운 분리를 나타내고, $z_{j}$ 는 층간 분리부의 위치를 나타낸다. 함수 $H\left(z-z_{j}\right)$ 는 heaviside unit step function이다. 층간 함수인 $A_{i}^{k}(z), B_{i}^{k}(z), \bar{C}_{i}^{k}(z)$ 는 전단 응력과 변위의 연속 조건 그리고 적층판의 윗면과 아래면에서의 전 단 응력의 경계조건을 이용해서 구할 수가 있고, 이
Table 2 Change of the natural frequencies

\begin{tabular}{c|c|c}
\hline \hline Mode & Healthy & Delaminated \\
\hline 1st & $40.5 \mathrm{~Hz}$ & $39.2 \mathrm{~Hz}$ \\
\hline 2nd & $125.3 \mathrm{~Hz}$ & $113.8 \mathrm{~Hz}$ \\
\hline 3rd & $251.3 \mathrm{~Hz}$ & $247.1 \mathrm{~Hz}$ \\
\hline 4th & $432.9 \mathrm{~Hz}$ & $406.8 \mathrm{~Hz}$ \\
\hline
\end{tabular}

함수들은 재료의 기하학적인 형상과 물성치의 정보 를 가지고 있다 $(i=1,2)^{(13)}$. 식 (1)의 향상된 층간 변 위장 모델과 유한요소법을 이용하여 다음과 같은 행 렬 형태의 운동방정식을 구할 수 있다 ${ }^{(10)}$.

$$
\begin{array}{r}
\mathbf{M} \ddot{d}_{u}+\mathbf{C} \dot{d}_{u}+\mathbf{K}_{u u} d_{u}+\mathbf{K}_{u \phi} d_{\phi}=\mathbf{F}_{u} \\
\mathbf{K}_{\phi u} d_{u}+\mathbf{K}_{\phi \phi} d_{\phi}=\mathbf{F}_{\phi}
\end{array}
$$

여기서, $d_{u}$ 는 유한요소의 절점 변위, $d_{\phi}$ 는 압전 층의 절점 전기장을 나타낸다. 매트릭스 $\mathbf{M}$ 과 $\mathbf{C}$ 는 질량과 감쇠행렬을 나타낸다. 매트릭스 $\mathbf{K}_{u \phi}$ 와 $\mathbf{K}_{\phi u}$ 는 압전-탄성 연성효과에 의해서 나타나는 강성 행렬이다. $\mathbf{K}_{u u}$ 는 구조물의 강성행렬, $\mathbf{K}_{\phi \phi}$ 는 압전 강성행렬을 나타낸다. 그리고, 벡터 $\mathbf{F}_{u}$ 와 $\mathbf{F}_{\phi}$ 는 기계적, 전기적 외력을 나타낸다. $\mathrm{MFC}$ 작 동기는 면내 방향(1번 방향)으로 $d_{33}$ 압전 효과를 사용하므로 Table 1에 $d_{11}$ 상수로 나타내었으며, 일반적인 압전 세라믹 모델과 달리 등가 전기장 모델을 적용하였다 ${ }^{(14)}$.

모드 해석을 통해 Fig. 1에서 제안된 구조물의 모 드 형상과 고유진동수를 확인하였다. 모드 해석은 구조물에 층간 분리가 존재하지 않는 건강한 상태 (healthy structure)와 층간 분리가 존재하는 손상된 상태(delaminated structure)에 대해서 각각 수행하였 다. 모드 형상은 두 경우 유사한 것으로 나타났으며, Fig. 2에 나타난 바와 같이 첫 번째와 세 번째는 굽 힘 모드가, 두 번째와 네 번째는 비틀림 모드가 발 생하였다. Table 2에 나타낸 바와 같이 손상이 있는 경우에는 건강한 상태보다 고유진동수가 낮아지는 경향을 가지는 것을 확인하였다. 이는 구조물에 존 재하는 층간 분리로 인해 전체 구조물의 강성이 낮 아짐에 따라 발생한 것으로 판단되며 주파수가 높은 고차 모드에서 주파수의 변화량이 커지는 특성을 나 타내었다. 


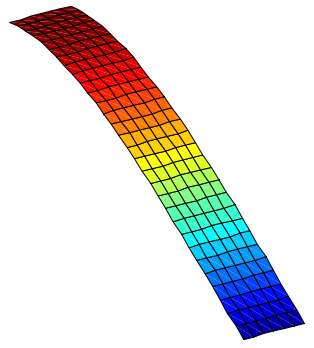

(a) 1st mode

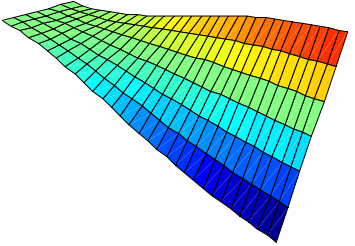

(b) 2nd mode

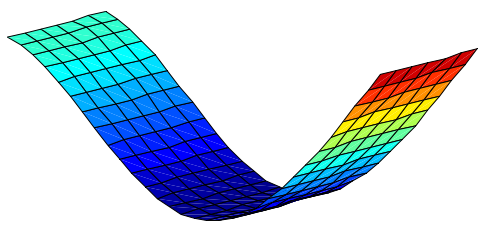

(c) 3rd mode

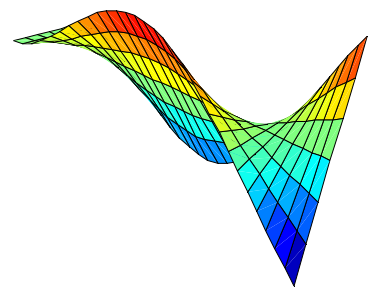

(d) 4th mode

Fig. 2 Mode shapes of the proposed composite structure

\section{3. 제어 성능 평가}

제어를 위한 시스템의 상태 공간 모델을 식 (2)의 운동방정식으로부터 다음과 구성하였다.

$$
\dot{\mathbf{x}}=\mathbf{A x}+\mathbf{B u}
$$

여기서 $\mathbf{A}$ 는 시스템 행렬, $\mathbf{B}$ 는 입력 행렬, $\mathbf{u}$ 는 제어 입력 행렬이다. 이 연구에서는 모든 상태 변수 는 측정 및 피드백이 가능하고, 제어 입력은 제한되 어 있지 않다는 가정을 바탕으로 pole placement 제
어 알고리듬을 적용하였다. 제어 입력 $\mathbf{u}$ 는 다음과 같이 Ackermann의 공식으로부터 결정되었다.

$$
\mathbf{u}=-\mathbf{K} \mathbf{x}
$$

$$
\begin{aligned}
& \mathbf{K}=\left[\begin{array}{llllll}
0 & 0 & 0 & \cdots & \cdots & 1
\end{array}\right]\left[\begin{array}{c}
\mathbf{B} \\
\mathbf{A B} \\
\mathbf{A}^{2} \mathbf{B} \\
\vdots \\
\vdots \\
\mathbf{A}^{n-1} \mathbf{B}
\end{array}\right] \phi(\mathbf{A}) \\
& |s \mathbf{I}-(\mathbf{A}-\mathbf{B K})|=\left(s-\mu_{1}\right) \cdots\left(s-\mu_{n}\right) \\
& =s^{n}+\alpha_{1} s^{n-1}+\alpha_{2} s^{n-2}+\cdots+\alpha_{n-1} s+\alpha_{n}=0 \\
& \phi(\mathbf{A})=\mathbf{A}^{n}+\alpha_{1} \mathbf{A}^{n-1}+\cdots+\alpha_{n-1} \mathbf{A}+\alpha_{n} \mathbf{I}
\end{aligned}
$$

손상이 없는 건강한 상태의 구조물과 손상이 있 는 구조물의 초기 상태의 극점의 위치를 Fig. 3에 나타내었다. 건강한 상태의 구조물의 극점은 $\mathrm{O}$ 로, 손상이 있는 구조물의 극점은 X로 나타내었으며, 4 개 모드에 대한 극점을 나타내었다. 구조물에 손상 이 있는 경우 극점의 위치가 오른쪽으로 이동한 것 을 확인할 수 있으며, 이는 Table 2에 나타난 바와 같이 구조물의 고유진동수가 감소한 것을 나타낸다. 첫 번째 모드의 경우 건강한 상태와 손상이 있는 상 태의 극점이 같은 위치에 있는 것처럼 보이지만, 실 제로는 다른 위치에 존재한다. 이는 Table 2에 나타 난 바와 손상된 구조물의 첫 번째 모드의 경우 고유 진동수 변화량이 작아서 생긴 현상이다.

제안된 시스템의 제어 성능을 평가하기 위하여 특정 모드로 초기 변위를 설정하고 구조물을 가진한 후 제어기를 실행하여 구조물의 주파수 응답을 관찰 하였다. 첫 번째 모드로 가진하고 첫 번째 모드만 제어를 수행한 경우의 주파수 응답 특성을 Fig. 4에 나타내었다. 건강한 상태 구조물의 응답을 파선 (dashed line), 손상이 있는 구조물의 응답을 점선 (dotted line), 손상이 있는 구조물을 제어한 경우의 응답을 실선(solid line)으로 나타내었다. 손상이 있 는 구조물의 응답은 건강한 상태의 응답보다 고유진 동수가 낮아졌으며, 이는 Table 2에 나타난 결과와 일치한다. 또한 손상이 있는 구조물에 제어를 수행 한 후에는 건강한 상태의 구조물 응답과 완벽히 일 치하는 것을 확인할 수 있다. 첫 번째 모드와 세 번 


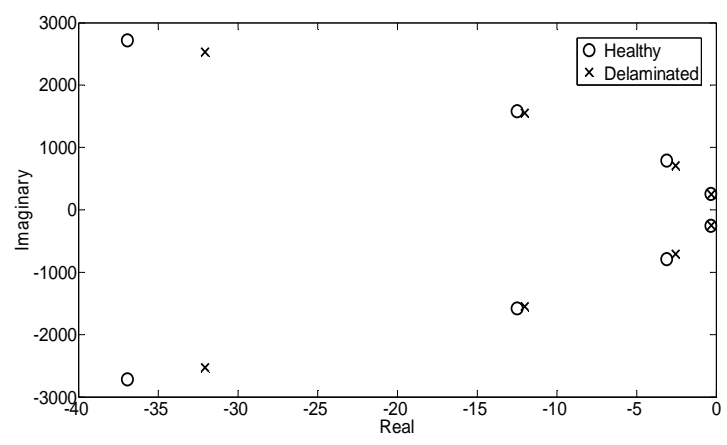

Fig. 3 Pole locations for healthy and delaminated structure

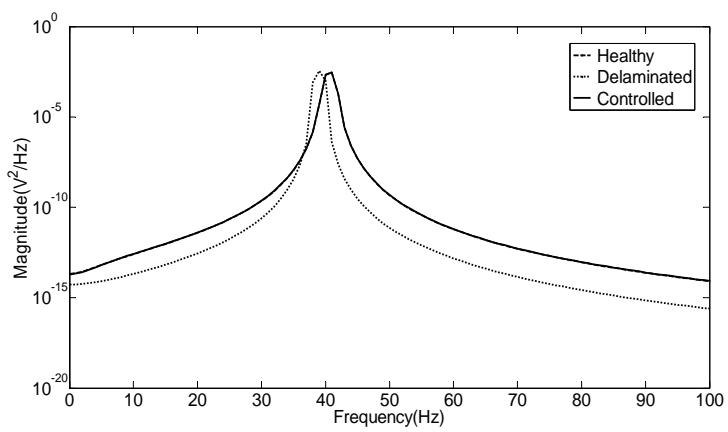

Fig. 4 Frequency response: first mode excitation and first mode control

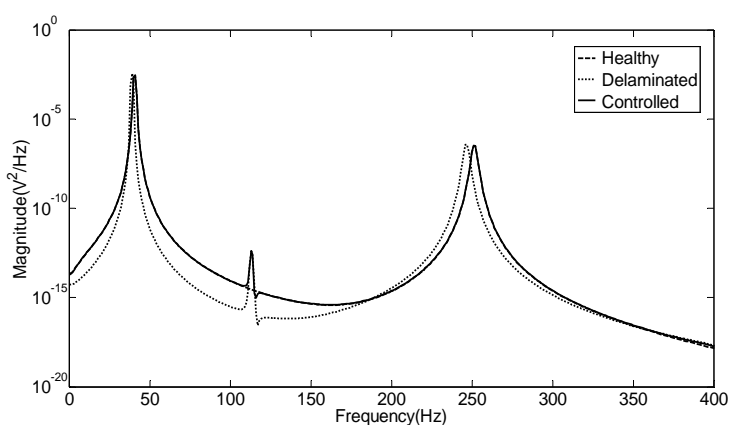

Fig. 5 Frequency response: first and third mode excitation, first and third mode control

째 모드로 동시에 가진하고 첫 번째 모드와 세 번째 모드를 제어한 경우에 대한 구조물의 응답은 Fig. 5 에 나타내었다. 구조물에 손상이 있는 경우, 첫 번 째와 세 번째 모드 모두 고유진동수가 낮아진 것을 확인할 수 있으며, 제어를 수행한 경우 손상이 없는 건강한 상태의 구조물 응답과 일치하는 것을 확인할 수 있다. 첫 번째 모드부터 네 번째 모드까지 동시에

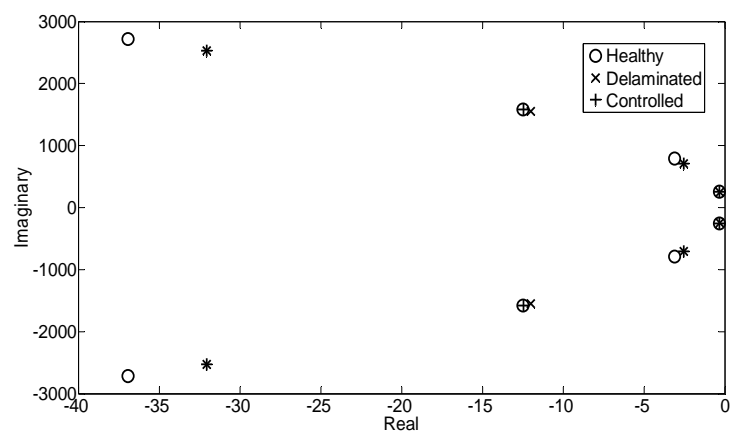

(a) First four modes

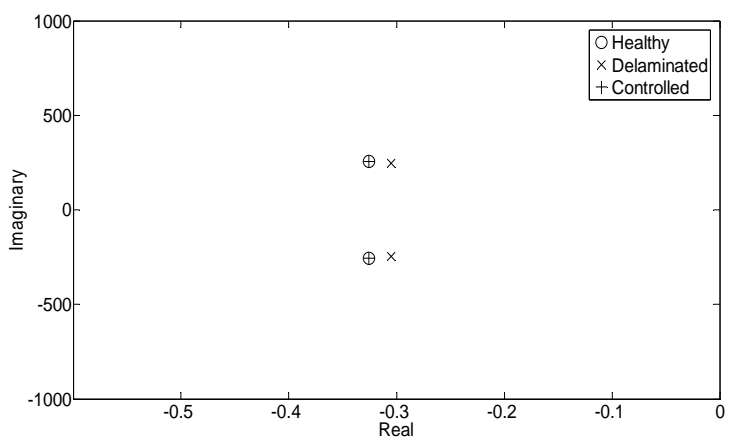

(b) 1 st mode

Fig. 6 Change of the pole locations

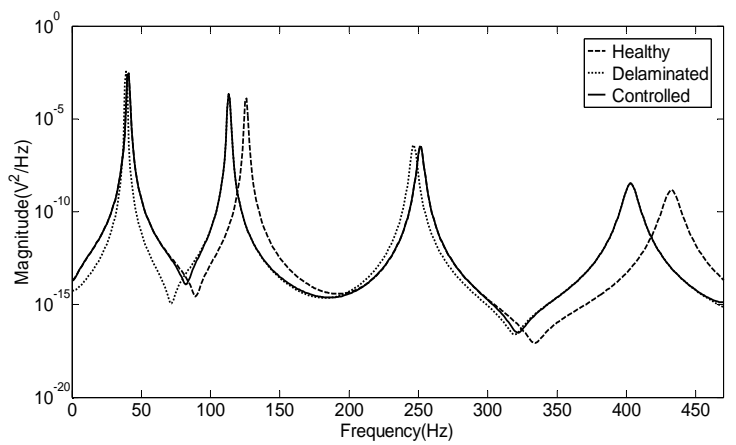

Fig. 7 Frequency response: from first to fourth mode excitation, first and third mode control

모두 가진하고 첫 번째 모드와 세 번째 모드를 제어 한 경우에 대한 시스템의 극점을 Fig. 6(a)에 나타내 었고, 첫 번째 모드에 대한 결과는 Fig. 6(b)에 확대 하여 나타내었다. 구조물에 손상이 발생한 경우 각 모드에 대한 극점이 오른쪽으로 이동한 것을 확인할 수 있으며, 제어를 수행하여 건강한 상태의 극점으 로 복원된 것을 확인할 수 있다. 제어를 수행하지 않은 두 번째와 네 번째 모드의 극점은 손상된 


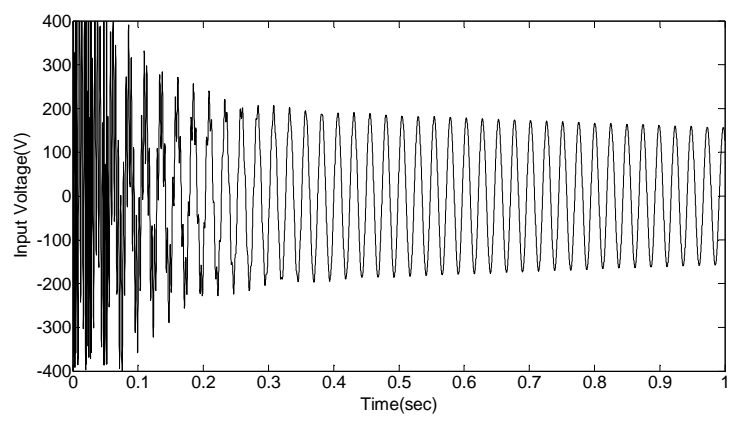

Fig. 8 Control input histories

Table 3 Recovery of the natural frequencies

\begin{tabular}{c|c|c|c}
\hline \hline Mode & Healthy & Delaminated & Controlled \\
\hline 1st & $40.5 \mathrm{~Hz}$ & $39.2 \mathrm{~Hz}$ & $40.5 \mathrm{~Hz}$ \\
\hline 2nd & $125.3 \mathrm{~Hz}$ & $113.8 \mathrm{~Hz}$ & $113.8 \mathrm{~Hz}$ \\
\hline 3rd & $251.3 \mathrm{~Hz}$ & $247.1 \mathrm{~Hz}$ & $251.3 \mathrm{~Hz}$ \\
\hline 4th & $432.9 \mathrm{~Hz}$ & $406.8 \mathrm{~Hz}$ & $406.8 \mathrm{~Hz}$ \\
\hline
\end{tabular}

구조물 극점 위치에서 이동하지 않았다. 이러한 경 우에 대한 구조물의 주파수 응답 특성을 Fig. 7에 나타내었다. 각 모드에서 손상에 의하여 고유진동수 가 낮아지는 것을 확인할 수 있으며, 제어를 수행하 여 첫 번째 모드와 세 번째 모드의 고유진동수가 건 강한 상태의 고유진동수로 회복되는 것을 확인할 수 있다. 두 번째 모드와 네 번째 모드의 고유진동수는 제어를 수행하지 않아 손상된 상태에서 복원되지 않 은 것을 확인할 수 있다. 건강한 구조물, 손상이 있 는 구조물, 제어를 수행한 구조물에 대한 고유진동 수 변화를 Table 3에 나타내었다. 첫 번째 모드와 세 번째 모드의 고유진동수가 건강한 상태와 동일하 게 복원된 것을 확인할 수 있다. 이때 $\mathrm{MFC}$ 작동기 에 인가된 제어 입력을 Fig. 8에 나타내었다. 제어 초기 최대 $400 \mathrm{~V}$ 의 전압이 인가되었으나, $200 \mathrm{~V}$ 이 하의 전압으로 제어가 효과적으로 수행되었다. 이 연구에서는 하나의 $\mathrm{MFC}$ 작동기가 폭 방향의 가운 데에 부착되어 있어 두 번째와 네 번째의 비틀림 모 드는 제어하지 않고, 첫 번째와 세 번째 굽힘 모드 만 제어를 수행하였다.

\section{4. 결 론}

이 연구에서는 층간 분리와 같은 손상이 적층 복
합재 구조물의 동적 특성을 변화에 주는 영향을 $\mathrm{MFC}$ 작동기와 능동제어 알고리즘을 이용하여 감소 시키고 구조물의 동적 특성을 유지할 수 있는지 평 가하였다. 향상된 층간 변위장 모델을 바탕으로 손 상이 있는 복합재 구조물의 유한요소 모델을 구축하 고, 건강한 상태와 손상이 있는 상태의 구조물에 대 한 모드 해석을 통하여 손상이 구조물의 모드 특성 변화에 주는 영향을 확인하였다. 제어 알고리즘을 바탕으로 $\mathrm{MFC}$ 작동기에 적절한 제어 입력을 인가 하여 층간 분리와 같은 손상이 구조물에 주는 영향 을 줄이고 건강한 상태의 구조물의 동적 특성을 유 지할 수 있는 것을 확인하였다. 향후 두 개 이상의 작동기를 사용하여 비틀림 모드의 제어에 대한 연구 를 진행할 것이며, 다양한 제어 알고리즘과 관측기 모델을 적용한 연구도 수행할 계획이다.

\section{후 기}

이 연구는 금오공과대학교학술연구비에 의하여 지원된 논문임.

\section{References}

(1) Giurgiutiu, V., Bao, J. and Zhao, W., 2003, Piezoelectric Wafer Active Sensor Embedded Ultrasonics in Beams and Plates, Experimental Mechanics, Vol. 43, No. 4, pp. 428 449.

(2) Giurgiutiu, V. and Zagrai, A., 2005, Damage Detection in Thin Plates and Aerospace Structures with the Electro-mechanical Impedance Method, Structural Health Monitoring-an International Journal, Vol. 4, No. 2, pp. 99 118.

(3) Cho, M. and Kim, J. S., 2001, Higher-order Zig-zag Theory for Laminated Composites with Multiple Delaminations, Journal of Applied MechanicsTransactions of the ASME, Vol. 68, No. 6, pp. 869 877.

(4) Chattopadhyay, A., Peralta, P., PapandreouSuppappola, A. and Kovvali, N., 2009, A Multidisciplinary Approach to Structural Health Monitoring and Damage Prognosis of Aerospace Hotspots, Aeronautical Journal, Vol. 113, No. 1150, pp. 799 810. 
(5) Radu, A. G. and Chattopadhyay, A., 2002, Dynamic Stability Analysis of Composite Plates Including Delaminations Using a Higher Order Theory and Transformation Matrix Approach, International Journal of Solids and Structures, Vol. 39, No. 7, pp. 1949 1965.

(6) Swann, C. and Chattopadhyay, A., 2006, Optimization of Piezoelectric Sensor Location for Delamination Detection in Composite Laminates, Engineering Optimization, Vol. 38, No. 5, pp. 511 528.

(7) Campanelli, R. W. and Engblom, J. J., 1995, The Effect of Delaminations in Graphite/PEEK Composite Plates on Modal Dynamic Characteristics, Composite Structures, Vol. 31, No. 3, pp. 195 202.

(8) Saravanos, D. A. and Hopkins D. A., 1996, Effects of Delaminations on the Damped Dynamic Characteristics of Composite Laminates: Analysis and Experiments, Journal of Sound and Vibration, Vol. 192, No. 5, pp. 977 993.

(9) Lee, J., 2000, Free Vibration Analysis of Delaminated Composite Beams, Computers and Structures, Vol. 74, No. 2, pp. 121 129.

(10) Kim, H. S., Kim, J. and Choi, S. B., 2005, Study on Dynamic Characteristics of Delaminated Smart Composite Laminates, Transactions of the Korean Society for Noise and Vibration Engineering, Vol. 15, No. 4, pp. 395 403.

(11) Pingkarawat, K., Wang C. H. and Varley, R. J., 2012, Self-healing of Delamination Fatigue Cracks in Carbon Fiber-epoxy Laminate Using Mendable Thermoplastic, Journal of Materials Science, Vol. 47, No. 10, pp. 4449 4456.

(12) Pingkarawat, K., Wang, C. H. and Varley, R. J., 2012, Self-healing of Delamination Cracks in Mendable Expocy Matrix Laminates Using Poly[ethylene-co-methacrylic acid] Thermoplastic, Composites. Part
A. Applied Science and Manufacturing, Vol. 43, No. 8, pp. 1301 1307.

(13) Kim, H. S., Chattopadhyay, A. and Ghoshal, A., 2003, Dynamic Analysis of Composite Laminates with Multiple Delamination Using Improved Layerwise Theory, AIAA Journal, Vol. 41, No. 9, pp. 1771 1779.

(14) Sohn, J. W., Kim, H. S. and Choi, S. B., 2007, Vibration Suppression of Hull Structure Using MFC Actuators, Transactions of the Korean Society for Noise and Vibration Engineering, Vol. 17, No. 7, pp. 587 595.

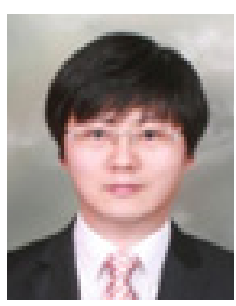

Jung Woo Sohn received his Ph.D. degree in the Department of Mechanical Engineering from Inha University in 2008. He is now working as an assistant professor in the Department of Mechanical Design Engineering of Kumoh National Institute of Technology. He has interest on the design and control of smart structures and systems.

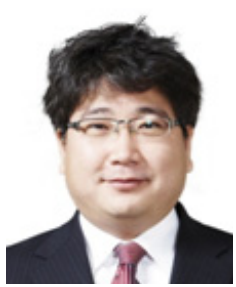

Heung Soo Kim received his Ph.D. degree in the Department of Mechanical and Aerospace Engineering from Arizona State University in 2003. He is now working as an assistant professor in the Department of Mechanical, Robotics and Energy Engineering, Dongguk University-Seoul. His main research interests are in biomimetic actuators and sensors, energy harvesting, smart materials and structures as applied to aerospace structures and vehicles. 